\title{
A different technique for sutureless coronary bypass grafting
}

\author{
TAMÁS RUTTKAY ${ }^{1, *}$, LÁSZLÓ BÁRÁNY ${ }^{1}$, ANDRÁS GRIMM ${ }^{1,2}$, LAJOS PATONAY ${ }^{1}$, \\ ÖRS PETNEHÁZY ${ }^{3}$, GERGELY RÁCZ ${ }^{4}$, GÁBOR BAKSA $^{1}$, ZOLTÁN GALAJDA ${ }^{5}$ \\ ${ }^{1}$ Laboratory for Applied and Clinical Anatomy, Department of Anatomy, Histology and Embryology, \\ Semmelweis University, Budapest, Hungary \\ ${ }^{2}$ Department of Otorhinolaryngology, Head and Neck Surgery, Semmelweis University, Budapest, Hungary \\ ${ }^{3}$ Medicopus Nonprofit Ltd., Kaposvár, Hungary \\ ${ }^{4} 1$ st Department of Pathology and Experimental Cancer Research, Semmelweis University, Budapest, Hungary \\ ${ }^{5}$ Department of Cardiac Surgery, Central Military Hospital, Bucharest, Romania \\ *Corresponding author: Tamás Ruttkay; Laboratory for Applied and Clinical Anatomy, Department of Anatomy, Histology and Embryology, \\ Semmelweis University, 26 Üllói St, H-1085 Budapest, Hungary; Phone: +36 l 4501500/53638; Fax: +36 l 2155158; \\ E-mail: ruttkay.tamas@med.semmelweis-univ.hu
}

(Received: May 13, 2019; Revised manuscript received: July 3, 2019; Accepted: July 8, 2019)

\begin{abstract}
Introduction: Many coronary anastomotic devices have been designed to replace manual stitching in coronary surgery; however, interestingly, none of them became widespread. Our aim was to work out an easy and fast endoluminal vessel-to-vessel stent bridge distal anastomotic technique. Materials and methods: Ten coronary arteries of eight fresh human hearts were used in this study. The anastomosis was performed with the implantation of a graft vessel into the lumen of the coronary artery by performing stent fixation. The technique is described and photo documented in detail. The durability and the conductibility of the anastomosis were examined with intraluminal endoscopy, functional streaming test, and a coloring of the vessels. Results: The anastomosis had great results in all cases. Obstruction, dissection, or dislocation of the vessels was not observable. Conclusions: This study confirmed the ex-vivo feasibility of the described technique. This method can be an easy, fast, and reliable method applied in the endoscopic distal coronary artery anastomosis surgery. The development of stents adapted to this method and the in-pivo testing of this technique are necessary for the future.
\end{abstract}

Keywords: sutureless anastomotic, coronary stent, coronary surgery, minimally invasive, vessel-to-vessel

\section{Introduction}

The tolerability of the coronary revascularization surgery has been improved by various new innovative technologies in the past few decades. The success of the off-pump coronary artery bypass grafting and the increasing number of the minimally invasive approaches (minimally invasive direct coronary artery bypass and totally endoscopic coronary artery bypass) indicate that coronary revascularization procedures will become fully endoscopic operations $[1,2]$.

Performing the distal coronary anastomosis is the most crucial step in the operation, the success of which influences the outcome of the patients the most. The classical stitching is the gold standard method; however, it is time- consuming and it requires a lot of experience even in the case of robot-assisted endoscopic approaches.

Many coronary anastomotic devices (C-Port Anastomotic System, Distal Connector, GraftConnector, $S^{2}$ Anastomotic System, and Magnetic Vascular Positioner) have been developed in order to simplify and speed up stitching. Interestingly, although the good functional outcome of surgeries using the above devices is confirmed by many clinical studies, they have not replaced classical stitching. Connecting these instruments to the coronary vessels is technically challenging and requires special, device-related experiences; therefore, their superiority in coronary surgery is questionable [3-19].

The aim of our workgroup was to develop a novel, endoluminal vessel-to-vessel stent bridge distal

This is an open-access article distributed under the terms of the Creative Commons Attribution-NonCommercial 4.0 International License, which permits unrestricted use, distribution, and reproduction in any medium for non-commercial purposes, provided the original author and source are credited, a link to the CC License is provided, and changes - if any - are indicated. (SID_1) 


\section{Ruttkay et al.}

anastomotic technique that does not require extensive experience from the surgeons, and which is highly standardizable and unaffected by the anatomical variations of the coronary and bypass-graft vessels.

\section{Materials and Methods}

Ten coronary arteries of eight fresh human cadaveric hearts were involved in this study. The cadavers had been donated to our institute for the purpose of education and medical research. The hearts were removed from the cadavers before the examinations. The ipsilateral internal thoracic artery was used for arterial bypass graft; its collateral branches were closed with ligature or hemoclip. The graft vessels were skeletonized in nine cases (90\%).

A coronary stent (TERUMO Tsunami Gold/Kaname, Leuven, Belgium) was introduced in the lumen of the graft vessel from its proximal end. The distal part of the stent was led through the vessel, only its proximal $5 \mathrm{~mm}$ remained in it. As a second step, the wall of the coronary artery was incised longitudinally $5-\mathrm{mm}$ long, and the stent-graft vessel complex was introduced into its lumen (Fig. Ia-c). After positioning the stent, the balloon was inflated with the prescribed pressure that pressed the stent and the graft vessel to the wall of the coronary artery and secured the anastomosis (Fig. Id).

\section{Methods of the anastomosis examination}

The applied examination methods are summarized in Table I.

\section{Pressure injection and functional streaming test}

The durability and conductivity of the anastomosis was controlled with pressure injection in all cases (100\%) and a functional streaming test was performed in one case (10\%). After removing the balloon, a silicone tube (inner diameter: $2 \mathrm{~mm}$ ) was connected to the proximal end of the graft vessel. Physiological saline was injected through the anastomosis with a syringe, and once again using a peristaltic pump. The initial streaming value was $20 \mathrm{ml} / \mathrm{min}$, and it was raised gradually by $20-80 \mathrm{ml} / \mathrm{min}$. The possible signs of leakage were controlled visually during the test.

\section{Intravascular endoscopy}

Later, the condition of the inner surface of the vessels was controlled with intravascular endoscopy after performing the anastomosis in one case (10\%). We used a $2-\mathrm{mm}$ diameter, $30^{\circ}$ rigid endoscope (Olympus A7006, Tokyo, Japan). Before the implantation, the graft vessel was stained with aniline blue (aniline blue; $0.5 \%$ acetic acid) for $90 \mathrm{~s}$, and dried at $37^{\circ} \mathrm{C}$ for $2 \mathrm{~min}$. This resulted in better visibility during the endoscopic examination.

\section{Examining the supply region of the anastomosis}

The coronary artery was injected through the anastomosis with colored latex (Kryolan, Berlin, Germany) in three cases $(30 \%)$ and with colored methyl-methacrylate (Acrifix 190, Darmstadt, Germany) in five cases $(50 \%)$. The hearts were fixed in $4 \%$ formalin solution for 4 weeks after the injection. The subepicardial branches

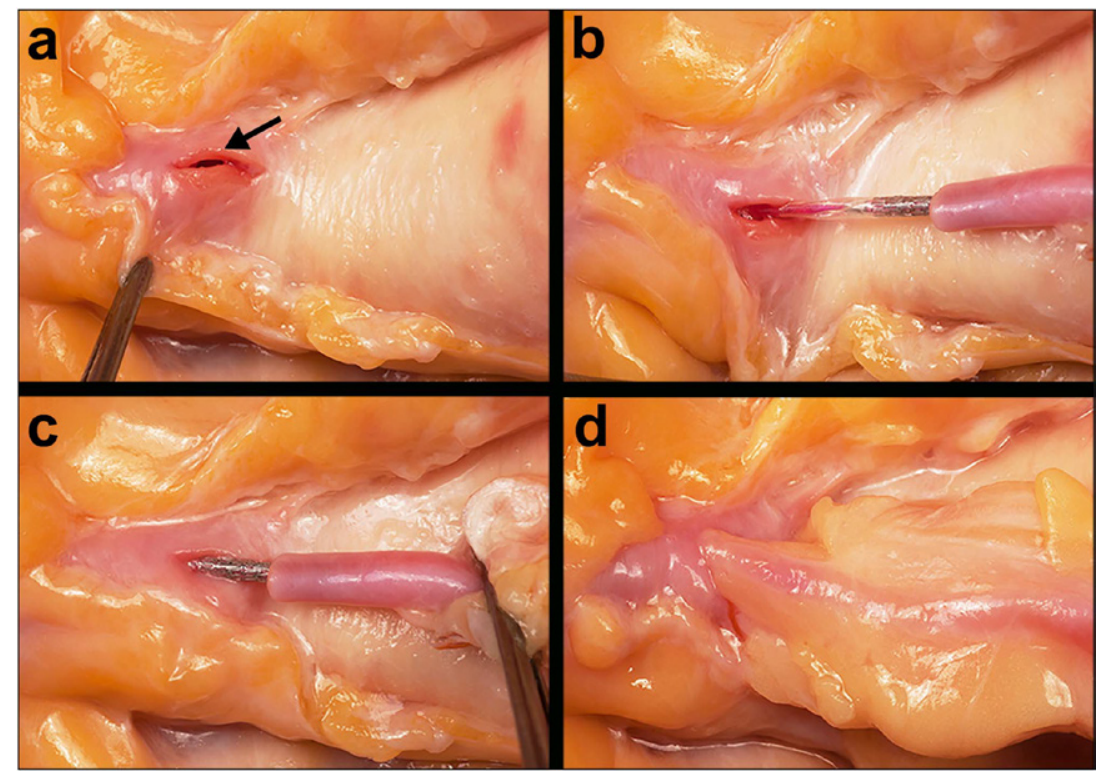

Fig. 1. Steps of the implantation. (a) Performing a 5-mm longitudinal incision on the proximal part of the right coronary artery (black arrow); (b and c) introduction of the graft-applicated stent into the lumen of the coronary artery; (d) a successful endoluminal vessel-to-vessel stent bridge anastomosis with a non-skeletonized internal thoracic artery 

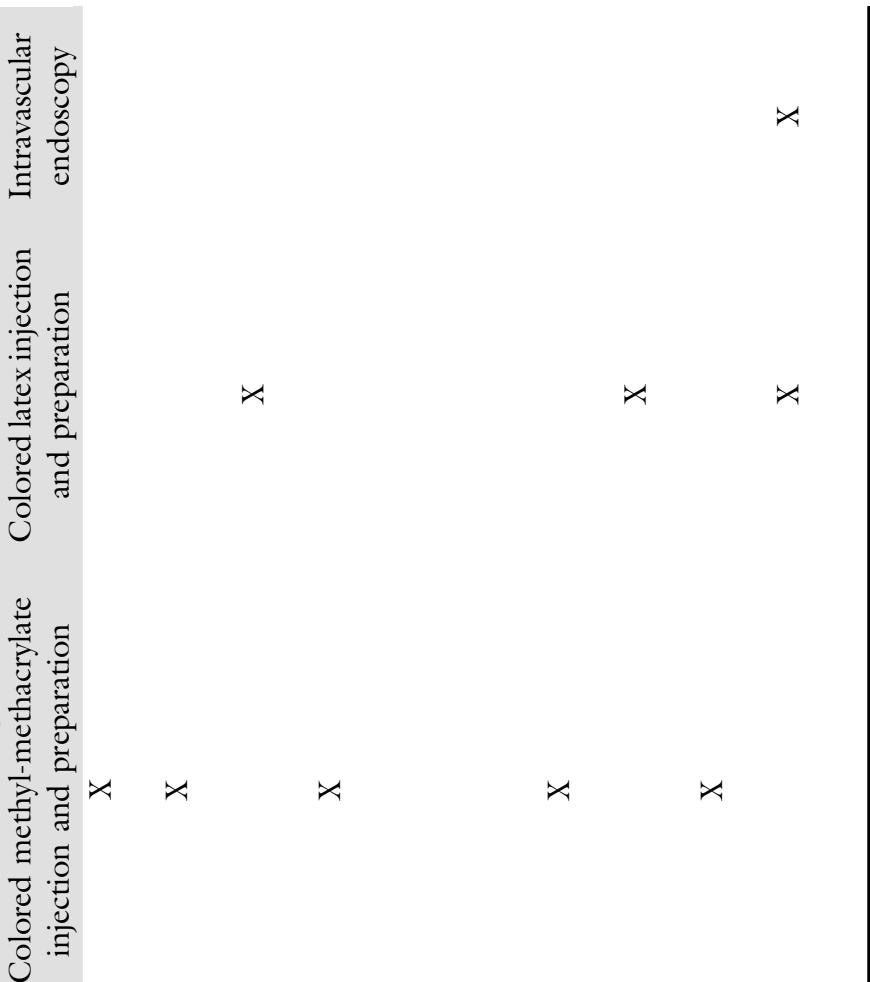

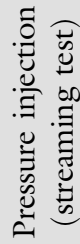

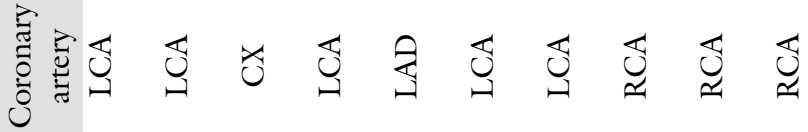

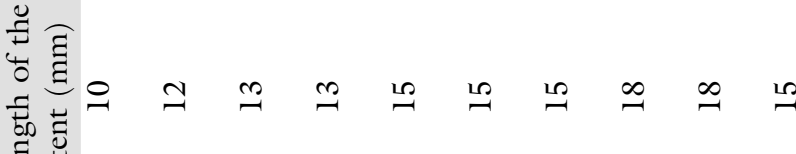
可

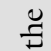

站

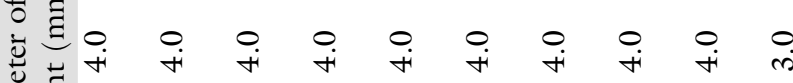
芯

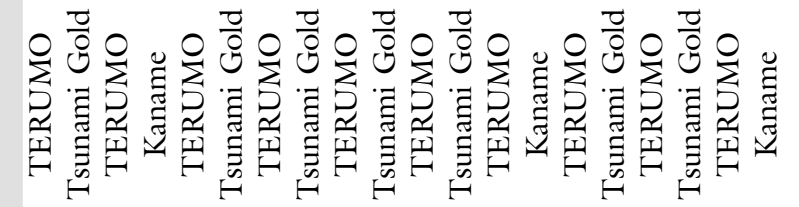

Hั0 
of the stented coronary arteries were prepared after the fixation in three cases $(30 \%)$.

\section{Preparation of the anastomosis}

The anastomosis involving the distal part of the graft and the proximal part of the coronary artery was removed in the eight formalin-fixed cases $(80 \%)$. The wall of the vessels was windowed in a prolonged rectangular shape to investigate the stent and its relation to the coronary and graft vessels.

The authors of this manuscript have certified that they comply with the principles of ethical publishing in Interventional Medicine \& Applied Science: Szél Á, Merkely B, Hüttl K, Gál J, Nemes B, Komócsi A: Statement on ethical publishing and scientific authorship. IMAS 2, 101-102 (2010).

\section{Results}

The endoluminal vessel-to-vessel stent bridge anastomosis was quick and easy to perform in all cases (100\%). There were no difficulties introducing the stent-graft vessel complex into the coronary artery, nor when inflating the balloon. The securing of the anastomosis was performed safely and correctly in all cases (100\%). There was no evidence of a rupture or dissection of the graft. The anastomosis functioned well during pressure injection and streaming test in all cases $(100 \%)$. There was no observable leakage or dislocation. Intravascular endoscopy provided the intraluminal control of the anastomosis. We found no obstruction in the lumen of the anastomosis, nor any injury on the inner walls of the vessels (Fig. 2). The subepicardial branches of the injected coronary artery were filled completely in all cases (100\%). Preparing them was easy to perform, verifying the ideal conductibility of the anastomosis (Fig. 3a). The different parts of the anastomosis were clearly distinguishable after the windowing (Fig. 3b).

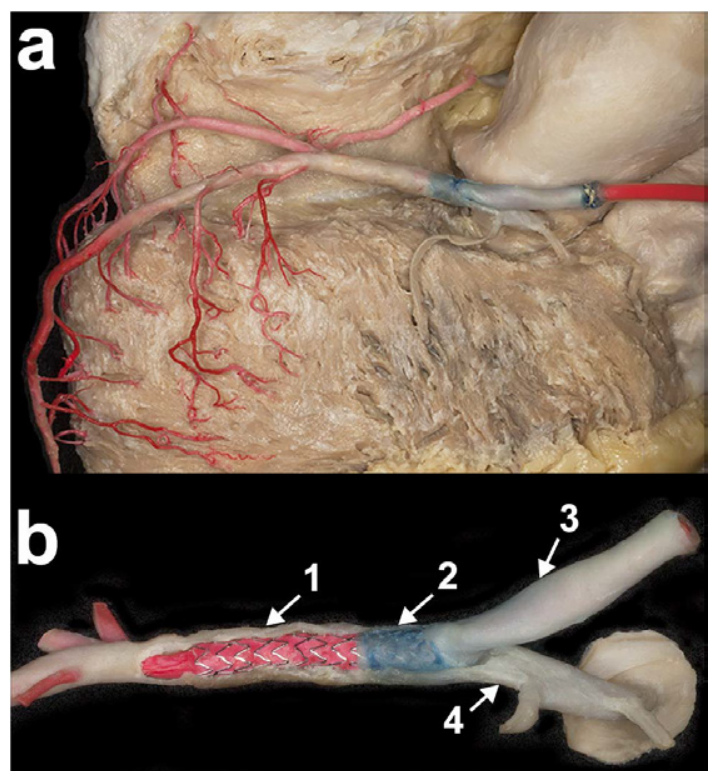

Fig. 3. Dissected specimen after a successfully performed endoluminal vessel-to-vessel stent bridge anastomosis and injection. (a) The subepicardial branches of the coronary artery filled with red-colored latex. (b) The fenestrated anastomosis: (1) distal part of the stent bridge anastomosis, (2) the intracoronary part of the internal thoracic artery, (3) extracoronary part of the internal thoracic artery, (4) proximal part of the right coronary artery

\section{Discussion}

Fully endoscopic and robot-assisted surgical approaches became available in the past decades due to the intensive technical development in medicine $[1,2]$. However, they did not address the disadvantages of the classic suture technique: the requirement of extensive experience and its time-consuming nature. Many sutureless anastomotic techniques were developed in the past to reduce stitching time and to standardize this crucial step of the operation, but all of them require a specially designed implanting device, and therefore require device-related expertise $[3,4]$. Some of them were performed using a complex clip-applier around the distal end of the graft vessel with an array of separate

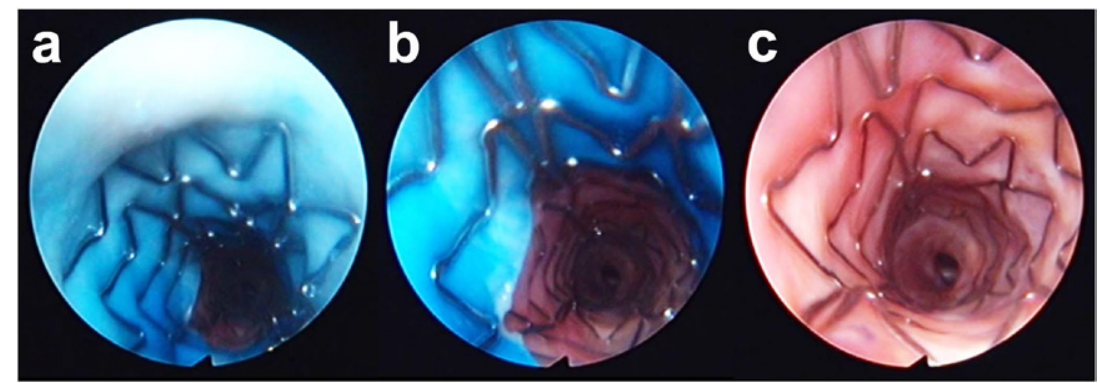

Fig. 2. Intraluminal endoscopic visualization of the endoluminal vessel-to-vessel stent bridge anastomosis. (a) The aniline blue tinctured internal thoracic artery with the proximal end of the implanted stent. (b) The transition between the graft and the coronary artery. (c) The distal part of the anastomosis 
microclips $[5,6]$ or an annular connector with hooks $[7,8]$ as well as staples $[9,10]$. To perform end-to-side sutures, there is a T-shaped connector device applied with polytetrafluoroethylene-covered coronary stent $[11,12]$. Other ones need a magnetic vascular positioner $[13,14]$ or an excimer-laser-assisted non-occlusive anastomosis coronary connector [15], both of which are able to replace handsewn side-to-side anastomosis. Interestingly, neither of these methods, nor other pilot methods [16-19] became generally accepted in daily clinical practice.

Our workgroup developed a novel sutureless distal coronary anastomosis technique that proved easy, fast, and reliable during the ex-vivo tests. Our technique requires no special implanting or fixing instruments: the graft vessel is secured in the coronary artery with the help of a coronary stent, the implantation of which is a routine procedure nowadays. This technique would be easily adaptable to the anatomy of the patient with the modulation of the diameter and the length of the stent, and would utilize the benefits of a hybrid operation room.

In our concept, further development of the intruments will result in a special stent and catheter system that makes accessible the distal end of the harvested internal thoracic artery through a femoral or radial artery puncture. Anchoring the distal end of the graft vessel with the special stent, we will be able to introduce it into the coronary artery. However, we used a longitudinal incision; we are developing a novel coronary puncture method similar to the Seldinger technique. The internal thoracic artery can be harvested using minimally invasive $(1-2 \mathrm{~cm})$ thoracoscopic ports without destroying the integrity of the patient's chest. Our method is performable using normal thoracoscopic instruments. There is no need of suturing and therefore it is unnecessary to use robotic assistance.

\section{Limitations of the technique}

The endoluminal vessel-to-vessel stent bridge anastomosis technique could be applied especially in cases of critically or totally obstructed coronary arteries. The positioning of the stent-graft complex in the coronary artery is most the crucial step of our technique. The anastomosis should be performed immediately distal to the critical obstruction, because the wall of the graft completely closes the coronary artery in the proximal direction. Imprecise implantation could close the branches of the coronary artery as well as the anastomosis. In case of bleeding from the proximal part of the coronary vessel, its clipping next to the anastomosis should be performed.

Our method, which proved feasible ex vivo, is a novel concept for the sutureless coronary anastomosis surgery. The examination of the in-vivo feasibility of our technique with specially designed stents is necessary and planned in the future.

$$
* * *
$$

\section{Funding sources: None.}

Authors' contribution: TR and ZG involved in project development, data collection, data analysis, and manuscript writing. LB contributed to manuscript writing. ÖP, GR, AG, and GB involved in data collection. LP contributed to project development.

Conflict of interest: The authors declare that they were free from outside interests in controlling the design of the study, the acquisition of the data, the collection, analysis, and interpretation of the data, and had freedom to fully disclose all results. This research did not receive any specific grant from funding agencies in the public, commercial, or notfor-profit sectors. The authors declare that they have no conflict of interest in regard to this study.

\section{References}

1. Leonard JR, Rahouma M, Abouarab AA, Schwann AN, Scuderi G, Lau C, Guy TS, Demetres M, Puskas JD, Taggart DP, Girardi LN, Gaudino M: Totally endoscopic coronary artery bypass surgery: A meta-analysis of the current evidence. Int J Cardiol 261, 42-46 (2018)

2. Yang M, Wu Y, Wang G, Xiao C, Zhang H, Gao C: Robotic total arterial off-pump coronary artery bypass grafting: Seven-year singlecenter experience and long-term follow-up of graft patency. Ann Thorac Surg 100, 1367-1373 (2015)

3. Tozzi P, Corno AF, von Segesser LK: Sutureless coronary anastomoses: Revival of old concepts. Eur J Cardiothorac Surg 22, 565-570 (2002)

4. Soylu E, Harling L, Ashrafian H, Attaran S, Athanasiou C, Punjabi PP, Casula R, Athanasiou T: A systematic review of the safety and efficacy of distal coronary artery anastomotic devices in MIDCAB and TECAB surgery. Perfusion 31, 537-543 (2016)

5. Matschke KE, Gummert JF, Demertzis S, Kappert U, Anssar MB, Siclari F, Falk V, Alderman EL, Detter C, Reichenspurner H, Harringer W: The Cardica C-Port System: Clinical and angiographic evaluation of a new device for automated, compliant distal anastomoses in coronary artery bypass grafting surgery - A multicenter prospective clinical trial. J Thorac Cardiovasc Surg 130, 1645-1652 (2005)

6. Verberkmoes NJ, Wolters SL, Post JC, Soliman-Hamad MA, ter Woorst JF, Berreklouw E: Distal anastomotic patency of the Cardica C-PORT ${ }^{\circledR}$ xA system versus the hand-sewn technique: A prospective randomized controlled study in patients undergoing coronary artery bypass grafting. Eur J Cardiothorac Surg 44, 512-518; discussion 518-519 (2013)

7. Eckstein FS, Bonilla LF, Schaff H, Englberger L, Windecker S, Hindrichs P, Carrel TP: Two generations of the St. Jude Medical ATG coronary connector systems for coronary artery anastomoses in coronary artery bypass grafting. Ann Thorac Surg 74, S1363-S1367 (2002)

8. Carrel T, Englberger L, Keller D, Windecker S, Meier B, Eckstein F: Clinical and angiographic results after mechanical connection for distal anastomosis in coronary surgery. J Thorac Cardiovasc Surg 127, 1632-1640 (2004)

9. Suyker WJ, Buijsrogge MP, Suyker PT, Verlaan CW, Borst C, Grundeman PF: Stapled coronary anastomosis with minimal intraluminal artifact: The S2 anastomotic system in the off-pump porcine model. J Thorac Cardiovasc Surg 127, 498-503 (2004)

10. Suyker WJ, Matonick JP, Suyker PT, de la Riviere AB, Buijsrogge MP, Budde RP, Verlaan CW, Pasterkamp G, Grundeman PF, Borst $\mathrm{C}$ : $\mathrm{S} 2$ connector versus suture: Distal coronary anastomosis remodeling, patency, and function in the pig. Circulation 114, I390-395 (2006)

11. Solem JO, Boumzebra D, Al-Buraiki J, Nakeeb S, Rafeh W, Al-Halees Z: Evaluation of a new device for quick sutureless 
coronary artery anastomosis in surviving sheep. Eur J Cardiothorac Surg 17, 312-318 (2000)

12. Tozzi P, Solem JO, Boumzebra D, Mucciolo A, Genton CY, Chaubert P, von Segesser LK: Is the GraftConnector a valid alternative to running suture in end-to-side coronary arteries anastomoses? Annals of Thoracic Surgery 72, S999-S1003 (2001)

13. Casselman FP, Meco M, Dom H, Foubert L, Van Praet F, Vanermen H: Multivessel distal sutureless off-pump coronary artery bypass grafting procedure using magnetic connectors. Ann Thorac Surg 78, e38-40 (2004)

14. Filsoufi F, Farivar RS, Aklog L, Anderson CA, Chen RH, Lichtenstein S, Zhang J, Adams DH: Automated distal coronary bypass with a novel magnetic coupler (MVP system). J Thorac Cardiovasc Surg 127, 185-192 (2004)

15. Stecher D, van Slochteren FJ, Hoefer IE, Pasterkamp G, Tulleken CA, van Herwerden LA, Buijsrogge MP: The nonocclusive laser-assisted coronary anastomotic connector in an off-pump porcine bypass model. J Thorac Cardiovasc Surg 147, 1390-1397 (2014)

16. Gundry SR, Black K, Izutani H: Sutureless coronary artery bypass with biologic glued anastomoses: Preliminary in vivo and in vitro results. J Thorac Cardiovasc Surg 120, 473-477 (2000)

17. Boening A, Schoeneich F, Lichtenberg A, Bagaev E, Cremer JT, Klima U: First clinical results with a 30 degrees end-to-side coronary anastomosis coupler. Eur J Cardiothorac Surg 27, 876-881 (2005)

18. Buijsrogge MP, Scheltes JS, Heikens M, Gründeman PF, Pistecky PV, Borst C: Sutureless coronary anastomosis with an anastomotic device and tissue adhesive in off-pump porcine coronary bypass grafting. J Thorac Cardiovasc Surg 123, 788-794 (2002)

19. Wippermann J, Konstas C, Wahlers T, Albes JM: Feasibility study of sutureless distal coronary anastomoses with degradable $\mathrm{Y}$-shunt and tissue adhesives in a porcine off-pump model. Interact Cardiovasc Thorac Surg 5, 676-679 (2006) 